УДК 338.22.021.1/338.246.2

ББК $65.2 / 4$

ВЗАИМОСВЯЗЬ СТРУКТУРНОЙ ПОЛИТИКИ ГОСУДАРСТВА И МОДЕРНИЗАЦИИ РЕАЛЬНОГО СЕКТОРА ЭКОНОМИКИ*

\author{
С. Ю. СОЛОДОВНИКОВ \\ solodovnicovs@tut.by \\ доктор экономических наук, профессор, заведующий кафедрой «Экономика и право» \\ Белорусский национальный технический университет \\ Минск, Республика Беларусь
}

В статье выявлена взаимосвязь структурной политики государства и модернизации реального сектора экономики, что позволило сделать вывод о необходимости парадигмальной замены модели выживания отечественных предприятий реального сектора экономики на модель новой индустриализации, т. е. на формировании новой структуры народного хозяйства, основой которой должен стать сверхиндустриальный промышленный уклад. Определены мероприятия, которые надо системно реализовать для создания оптимальных условий реализаџии этой модели в Республике Беларусь.

Ключевые слова: структурная политика, экономический рост, инновационное развитие, научно-техническая революция.

\title{
RELATIONSHIP OF STRUCTURAL POLICY OF THE STATE AND MODERNIZATION OF THE REAL SECTOR OF ECONOMICS
}

\author{
S. Yu. SOLODOVNICOV \\ Doctor in Economics, Professor, Head of the Chair «Economics and Law» \\ Belarusian National Technical University \\ Minsk, Republic of Belarus
}

В статье выявлена взаимосвязь структурной политики государства и модернизации реального сектора экономики, что позволило сделать вывод о необходимости парадигмальной замены модели выживания отечественных предприятий реального сектора экономики на модель новой индустриализации, т. е. на формировании новой структуры народного хозяйства, основой которой должен стать сверхиндустриальныий промышленный уклад. Определены мероприятия, которые надо системно реализовать для создания оптимальных условий реализачии этой модели в Республике Беларусь.

Ключевые слова: структурная политика, экономический рост, инновационное развитие, научно-техническая революция

\section{ВВЕДЕНИЕ}

В самом общем виде последствия от реализации структурной политики государства и изменений технико-технологической базы реального сектора экономики для национальной экономики могут заключаться в: 1) упрочении жизненности социума: переход к новому качеству экономического роста; устойчивое социально-экономическое развитие

\footnotetext{
* Выполнено при поддержке гранта, договор с БРФФИ № Г17АРМ-001 от «01» июня 2017 г. «Согласование структурной политики Беларуси и Армении в контексте модернизации реального сектора экономики»
} 
общества, поступательный экономический рост; повышение конкурентоспособности отечественных продуктов на внутреннем и внешнем рынках; ослабление социально-классовых антагонизмов; создание материальных и социальных предпосылок для противодействия информационному оружию; 2) снижении жизненности социума: экономическая деградация или же однобокий экономический рост каких-либо хозяйственных отраслей (например, нефтедобыча), ведущий не к долгосрочному и поступательному развитию экономической системы, а к ее перспективной деградации; усиление социально-классовых и иных антагонизмов; подверженность внешней информационно-идеологической экспансии, ведущей в конечном счете к гибели социума; уничтожение национального государства.

Для корректного научного изучения взаимосвязи структурной политики государства и модернизации реального сектора экономики, на наш взгляд, необходимо учитывать два обстоятельства: во-первых, сущностные (неслучайные, устойчивые, не временные и т. д.) изменения социально-экономической системы в любом социуме, как правило, происходят не моментально, а, напротив, требуют относительно продолжительного промежутка времени. С точки зрения гносеологии для того, чтобы избежать оберации близости, необходимо рассматривать изучаемое явление на достаточно продолжительном промежутке времени и, во-вторых, всякое научное обобщение имеет право на существование, лишь когда рассматривается достаточно большое количество объектов.

\section{РЕЗУЛЬТАТЫ И ИХ ОБСУЖДЕНИЕ}

Структурная политика государства выступает важнейшим компонентом стратегического планирования хозяйственной деятельности на уровне общества. «В стратегическом планировании важнейшей проблемой, - справедливо отмечают О. С. Сухарев и Е. Н. Стрижакова, - выступает возможность предвидения будущего и определения диапазона планирования. Цель такого планирования состоит в необходимости осуществления эффективного управления экономическими изменениями» [1, с. 9]. В таком случае стратегическое планирование в контексте структурной политики предполагает необходимость не только выработки достоверных футурологических технико-технологических прогнозов, но и определения того, как это повлияет на трансформацию общественных институтов, форм и способов реализации политико-экономических и коммерческих интересов, которые, в свою очередь, обладают известной самостоятельностью (особенно в формах реализации) по отношению к объективно определяющим их потребностям. Причем последние, в свою очередь, очень динамичны и относительно самостоятельны. По существу, такие определения как: субъект - носитель активности, интересы - направления деятельности, потребности - причина активности, хоть и являются при субстанционарногносеологическом подходе правильными, но при рассмотрении реальных социально-экономических феноменов оказываются излишне абстрактными и упрощенными.

При исследовании взаимосвязи структурной политики государства и модернизации реального сектора экономики следует избегать ошибок, характерных для ряда «классических подходов» к разработке стратегии развития экономической системы [2, с. 53], когда игнорируется инерция эволюционных изменений. Напротив, необходимо, вслед за О. С. Сухаревым и Е. Н. Стрижаковой, учитывать, «что планирование, стратегия - это и есть эволюционирующий вместе с системой элемент, а не что-то воздействующее на нее экзогенно. Следовательно, можно говорить о том, что разработка стратегии развития любого уровня экономики и подготовка плана должны включать имманентные особенности эволюционного процесса данного и сопряженных с ним уровней. В этом смысле происходит преобразование этапов решения стратегических проблем, включавших ранее: осознание необходимости решения проблемы, формулировку вариантов ее 
решения, оценку вариантов по критерию привлекательности, процедуру выбора одного или несколько вариантов. В названную схему добавляется еще один этап: выявление закономерностей эволюционного процесса системы и оценка потенциальной эффективности происходящих - управляемых и неуправляемых - изменений» [1, с. 10]. Таким образом, по мере реализации структурной политики, направленной на модернизацию реального сектора экономики, будет эволюционировать не только этот сектор, его технико-технологическая база, но и сама структурная политика. Причем эта трансформация может иметь принципиально разные последствия, а именно: либо инерция, традиции в формировании, методах, инструментах и формах реализации структурной политики будут все больше и больше отдалять эту политику от реального состояния объекта планирования, делая ее все менее и менее эффективной, либо сама эта стратегия должна достаточно быстро эволюционировать вслед за изменениями реального сектора экономики, встраиваясь в живой хозяйственный механизм, ориентируя его в направлении инновационного развития.

Необходимо учитывать, что «в теоретическом плане всегда существует проблема выбора между долгосрочными инвестициями в науку и в разработки <...>, а также текущей модернизацией производства (краткосрочная жизнеспособность)» [1, с. 10]. Председатель Сибирского отделения РАН, академик А. Л. Асеев подчеркивал: «Отказ от фундаментальных исследований - глубочайшее заблуждение. Достаточно вспомнить, что одной из причин поражения Германии во второй мировой войне стало то, что в 30 -е годы национал-социалисты, придя к власти, решили: фундаментальная наука не нужна, незачем на нее деньги тратить. К сожалению память у нас короткая... И Германия в области фундаментальных исследований допустила такое отставание, что до сих пор пользуется трудом зарубежных ученых, в том числе российских» [3, с. 18]. М. В. Мясникович отмечал что то, «что вкладываемые в науку средства в перспективе окупаются многократно, общеизвестно» [4]. И далее: «То есть, если мы, как страна, хотим иметь достойное и суверенное будущее, в основу своего развития мы должны поставить знания, развитие своего научно-технического потенциала. Поэтому с самого начала одной из стратегических задач Президента Республики Беларусь, Правительства нашей страны всегда было сохранение и развитие как фундаментальной, так и прикладной науки» [4]. Вместе с тем для любого экономиста-практика очевидно, что модернизировать производство надо сегодня и сейчас, а еще лучше - вчера. Из этого следует вывод, что перед органами государственного управления при разработке структурной политики (долгосрочная жизнеспособность) и политики технологической модернизации реального сектора экономики (краткосрочная жизнеспособность) всегда будет стоять задача определить оптимальное соотношения между ними. Любой перекос в этом плане неизбежно приведет к снижению жизненности экономической системы общества, социума в целом.

При реализации структурной политики наблюдаются две разновидности изменений. «Во-первых, запланированные изменения, которые обеспечены только внутриорганизационными решения и процедурами (правительственного или корпоративного уровня) и, во-вторых, изменения адаптации, которые происходят в результате перемен в отношениях с элементами внешней среды, касающихся как отдельных агентов экономики, так и экономики в целом» [1, с. 10-11]. Названная классификация изменений характерна и для изменений, возникающих в рамках взаимовлияния структурной политики государства и модернизации реального сектора экономики. Необходимо также учитывать то обстоятельство, что «область стратегического планирования и поведения непосредственно связана с прошлым опытом поведения - сохраненными в памяти системы управлениями схемами (моделями) поведения, принятия решений, включая планирование. При разработке стратегии развития системы очень важно учесть инерцию ее эволю- 
ции» [1, с. 11-12], поскольку «настоящее и будущее связаны с прошлым социальными институтами, а применительно к экономической системе: рутинами, памятью опытом и зафиксированными в них технологическими возможностями, и преимуществами» [1, с. 12]. Применительно к объекту нашего исследования - взаимосвязи структурной политики государства и модернизации реального сектора экономики - влияние инерционности значительно усиливается. Это обусловлено тем, что инерционность планирования структурной политики усиливается инерционностью промышленной, сельскохозяйственной и региональной политик, которые влияют на методы, формы, темпы и приоритеты модернизации реального сектора.

Помимо вышеназванных обстоятельств в настоящее время негативное влияние на совершенствование структурной политики государства в контексте модернизации реального сектора экономики оказывает отсутствие в экономической науке четких фундаментальных теоретических представлений о том, что же следует понимать под технологической эволюцией. В российской научной литературе эта гносеологическая проблема описывается так: «Известна идея - представить, технологическую эволюцию, как смену неких технико-экономических парадигм (К. Перес), в российской более поздней версии так называемых технологических укладов. Эти вещи ретроспективные, классификационные, это абстрактные схемы, ничего не проясняющие в технологическом развитии, поскольку никто ничего не может сказать о шестом (иногда и о пятом!), не говоря уже о седьмом или восьмом укладе (парадигме). Следовательно, пока точно не установлено, что составляет его основу (уклада), правдоподобно сказать о нем затруднительно, по крайней мере, на коротком отрезке времени. Только обернувшись назад, можно сказать о прошлых этапах, условно подразделяя их на некоторые периоды времени» [1, с. 12-13]. Иначе говоря, достаточно популярная сегодня концепция смены технологических укладов представляет собой ретроспективную концепт схему.

Однако этой идее придается вес не только как ретроспективной концепции-схеме [1, с. 12-13], а как основе для текущей экономической политики. Так, например, в работе «Нанотехнологии как ключевой фактор нового технологического уклада в экономике» [5], вышедшей в 2009 г., отмечается, что «всплеск и падение цен на энергоносители, мировой финансовый кризис - верные признаки завершающей фазы жизненного цикла доминирующего технологического уклада и начало структурной перестройки экономики на основе следующего уклада» [5, с. 17]. Оставляя в стороне вопрос, почему во время множества других мировых экономических кризисов, регулярно повторяющихся во второй половине XX, начале XXI веков и нередко сопровождаемых всплеском и падением цен на энергоносители (например, мировой кризис 1974-1975 гг.) - это не свидетельствовало о смене доминирующих технологических укладов, отметим только, что социальная парадигма смены технологических укладов категориально не описана. О. А. Наумович отмечает по этому поводу: «Однако, отсутствие стройных (внутренне непротиворечивых) понятийных рядов негативно сказывается в том плане, что любое, даже самое точное и совершенное определение (если оно не вписано адекватным образом в понятийный ряд, т. е. систему других взаимосвязанных понятий и категорий) не позволяет содержательно решить сложную многоуровневую задачу, не только раскрыть сущность того или иного технологического уклада как социально-экономического феномена, но и как определенной стадии развития человеческого общества, определенного этапа в развитии экономики, определенного этапа в развитии самого общества, жизни людей, политэкономически как феномена, но и одновременно раскрыть те факторы или сущность, почему оно возникло, т. е. его генезис» [6, с. 35]. Сложившаяся в экономической науке постсоветских стран после 1991 г. ситуация, характеризующаяся отказом многих ученых-эконо- 
мистов, работающих в конкретно-экономических направлениях, от теоретико-методологической проработки принципов своих исследований, создала условия для слепого копирования технологической политики западных стран. Например, если западные страны активно развивают наноиндустрию, то и мы будем поступать также. Ошибочность такого подхода в планировании сегодня критикуется многими учеными $[1,7-9]$. При этом справедливо подчеркивается, что в структурном и технологическом планировании «нужно учитывать текущее состояние базовых технологий» [7, с. 3-10], поскольку в ситуации резкого отставания от сверхиндустриальных стран базисных машиностроительных технологий, инженерной работы и оказания услуг промышленного характера, «никакие рецепты вложений в нанотехнологии не только нельзя назвать обоснованными, но они порождают дополнительные структурные перекосы и не являются отражением той системности действий и развития общих технологий, которые могут потребовать на следующем этапе и нанотехнологий, как неотъемлемого элемента в некотором объеме, который будет задан масштабом и потребностями экономики, ее общей технологичностью» $[1, \mathrm{c.} 13]$.

В частности, отдача от опережающего развития услуг промышленного характера («опережающий характер развития этих услуг позволяет обеспечивать формирование нового национального промышленного комплекса, основывающегося на наукоемких высокотехнологичных и среднетехнологичных (высокого уровня) отраслях и модернизированных в сторону повышение доли добавленной стоимости, снижение материалоемкости и импортоемкости традиционных отраслях промышленности» [10, с. 84-85]), не только способствует формированию современной структуры экономики, но и может принести куда больший эффект для модернизации реального сектора. Ю. В. Мелешко справедливо отмечает по этому поводу: «В контексте четвертой промышленной революции значение услуг промышленного характера в формировании конкурентоспособности промышленных предприятий увеличивается, поскольку именно благодаря этим услугам может быть организовано эффективное производство нового типа («умные заводы») и реализована клиентоориентированная (в широком смысле) политика предприятий» [11, с. 78]. Названный автор также подчеркивает, что в современных условиях «инновационная активность предприятий промышленного комплекса напрямую зависит от использования услуг промышленного характера, при помощи которых решается задача повышения конкурентоспособности промышленной продукции путем совершенствования производственного процесса на всей цепочке создания стоимости» [12, с. 143]. При этом следует принимать во внимание, что развитие услуг промышленного характера не требует таких больших инвестиций как создание наноиндустриии, позволяет быстро окупаться, а также приносит дополнительные положительные синергетические эффекты.

Иначе говоря, если структурная политика государства направлена на научно обоснованное опережающее развитие услуг промышленного характера, то модернизация реального сектора экономики будет проходить быстрее, последовательнее и потребует относительно меньших издержек, чем в случае, когда структурная политика ориентируется на достижение мифологизированной (т. е. научно не обоснованной цели достижения 6,7 или еще какого-то более высокого технологического уклада в стремлении идти по пути экономически развитых стран). О. С. Сухарев и Е. Н. Стрижакова справедливо замечают, что «слабо обоснованные теоретические позиции являются основанием для ошибок и неверного выстраивания текущей экономической и в частности научно-технической политики государства» [1, с. 13].

Существующие сегодня в Республике Беларусь институты, отвечающие за функционирование органов планирования социально-экономического развития, будут оказывать значительное влияние как на разработку и реализацию структурной политики госу- 
дарства, так и на модернизацию реального сектора экономики. «Оценка структурной динамики представляется важнейшей научно-практической задачей, поскольку по большому счету стратегические проблемы социально-экономического развития развертываются вокруг двух векторов: население имеет желание жить комфортно (благоустроенно, с недорогим доступом к важнейшим социальным функциям), социально-экономическая инфраструктура должна отражать и удовлетворять основные потребности граждан, в том числе в творческом труде. По этой причине определяющим условием развития выступает укрепление промышленной базы, занятости и стимулирование роста доходов населения, создание дохода посредством продуктивной деятельности (ибо непродуктивная деятельность не доставляет комфорта)» [1, с. 24].

Решить эту проблему рыночными инструментами невозможно, поскольку проведение модернизационной структурной политики подразумевает концентрацию ресурсов на секторах экономики и отдельных экономико-образующих предприятиях, которые должны обеспечить технико-технологическую модернизацию страны, а логика современного рынка (когда крупные предприятия, как правило, находятся в акционерной, т. е. коллективной собственности) требуют от руководства частных компаний обеспечивать постоянный рост капитализации организации (рост котировки акций более быстрый, чем у конкурентов на рынках ценных бумаг), повышение ее доходности и т. д. Иначе говоря, здесь постоянно наблюдается конфликт интересов при определении приоритетов, а именно: на чем сконцентрировать ресурсы - на текущем росте или на стратегическом развитии. При этом возрастают риски невыполнения планов по структурной перестройке экономики в целом, реального сектора в частности. К тому же, «переход к новым общественно-технологическим укладам, начинающим играть доминирующую роль в социуме, а именно это подразумевается под категорией "новое качество экономического роста", обязательно вызывает нарушение баланса социально-экономических интересов, активизацию борьбы различных социальных групп и классов за оптимизацию реализации своих интересов в новых политико-экономических реалиях» [13, с. 57].

Экономически развитые страны в свое время все оказывались перед необходимостью ограничения рыночных инструментов хозяйствования в условиях проведения технологической модернизации, все они решали эту задачу с учетом национальной и исторической специфики, но всегда при этом ограничивали стихию саморегулирующегося рынка. В частности, как отмечает М. В. Афанасьева, сегодня «выявлена ранее неизвестная структурная особенность процесса успешного развития технологически отстающих стран, в частности послевоенной Японии и ей подобных, выражающаяся в двух этапах совершенствования качества экономической системы, отличающихся целевой направленностью и методами решения задач развития. На первом этапе проводилась политика целостного развития экономики, и только в тактическом плане выделялись временно приоритетные отрасли. На втором - государственная помощь крупным корпорациям (прямые субсидии и обеспечение беспрецедентно дешевых кредитных ресурсов) обеспечила технологическое развитие страны в целом. Меры государственного регулирования обеспечили прирост национального капитала и направили деятельность и амбиции деловой элиты на развитие собственной экономики за счет внутренних ресурсов страны» [14, с. 7].

Предоставляя в условиях структурной перестройки экономики формирование хозяйственных пропорций рыночным «саморегулирующимся» механизмам «можно породить стохастический процесс развития, с высокой вероятностью крушения планов, пересмотра предпочтений, растраты ресурсов, которая может превзойти потери от неверного планирования экономической политики» [1, с. 25]. Без активного вмешательства органов государственного управления невозможна «осознанная постановка целей, функциональное обеспечение развивающейся системы управления, оптимизация затрат, повышение 
устойчивости (адекватности и адаптивности при принятии решений), обоснованность мероприятий (опора на расчеты, включая расчет и оценки различных видов эффективности), точность в формировании области приложения усилий, учет времени принятия решений и синхронизации действий, снятие факторов сопротивления и учет вероятности отторжения отдельных решений и векторов движения (экзогенная и эндогенная устойчивость), оценка прогнозных сценариев (вариантов) развития, составляют те необходимые критерии стратегического планирования, которые могут быть реализованы не в виде дополнительной нагрузки уже действующим подразделениям правительства (органам управления), а при систематической работе в рамках координирующей правительственной планирующей структуры» [1, с. 25].

Структурная политика, ориентированная на модернизацию реального сектора экономики, может реализовываться только на основе новой индустриализации, обеспеченной современной системой государственного планирования и управления, с широким привлечением к этому процессу институтов общественно-государственно-частного партнерства и мобилизации для этого процесса необходимых социальных, человеческих, материальных, финансовых, предпринимательских и институциональных ресурсов. В свою очередь, новая индустриализация (иначе говоря, технико-технологическая и институциональная модернизация реального сектора экономики), развивая производственные способности и потребности индивидов, сама будет выступать важным фактором, определяющим границы, направления и темпы структурной эволюции экономики. Это обусловлено тем, что сверхиндустриальная экономика предъявляет новые требования к рабочей силе, а быстро меняющиеся производственные и потребительские потребности, в свою очередь, обусловливают быстрое, а иногда революционное, изменение способностей индивидов. Все это порождает массу синергетических эффектов, многие из которых невозможно предсказать. Например, в условиях новой индустриальной революции «усиление требований к интеллектуальному уровню рабочей силы, а также к интеллектуализации рабочего места, влечет за собой изменения в системе подготовки и развития рабочей силы, а также изменения в рамках всей системы производство-распределение-обмен-потребление. Новые технологии расширяют и возможности современных предприятий. Так, в ближайшем будущем те же 3D-принтеры можно будет использовать не только на территории предприятий, но и непосредственно в месте потребления создаваемой с их помощью продукции, например, на строительной площадке, при «печатании» строительных конструкций» [15, с. 17]. Н. Ю. Лебедин так описывает ряд важнейших последствий появления и внедрения новых технологий: «Под влиянием новых технологий и роста числа людей, готовых к их практическому применению, создается целая индустрия самостоятельного использования сервисов, что, в конечном счете, стирает границы между производителем и потребителем, между обслуживающим персоналом и клиентом. Это становится фактором воздействия на человека и предполагает решение, как минимум, двух взаимосвязанных задач: формирование работника, не только соответствующего новым требованиям, но и способного эти требования создавать; перераспределение работников между отраслями производства благодаря возможностям Интернет-технологий и роботизации» [15, с. 17].

Модернизация реального сектора экономики неизбежно ведет к сокращению числа занятых в этом секторе при значительном росте производительности труда, что вызывает соответствующие изменения в структуре экономики. В «США за последние полтора десятилетия численность рабочей силы в производственном секторе снизилась более чем на 40 \% (при кратном увеличении количества используемого высокотехнологичного оборудования). < ..> В сфере обслуживания снижение численности работников 
было более умеренным и составило 15 \%, при значительном увеличении масштабов самой сферы. Это сопровождалось созданием новых рабочих мест в масштабе, значительно превышающим указанное снижение. Доля базовых отраслей национального хозяйства (добыча полезных ископаемых, обрабатывающая промышленность, энергетика, транспорт, сельское хозяйство, строительство) в валовой добавленной стоимости снизилась до 45 \% к настоящему времени с 70 \% в 70-е годы XX века» [15, с. 17]. Таким образом, существует взаимозависимость между структурной политикой и модернизацией реального сектора экономики.

Структурная политика в Республике Беларусь должна основываться на парадигмальной замене модели выживания отечественных предприятий реального сектора экономики на модель новой индустриализации, т.е. на формирование новой структуры народного хозяйства, основой которой должен стать сверхиндустриальный промышленный уклад. Российские исследователи отмечают, что при смене «модели выживания на модель реструктуризации промышленности» $[16$, с. 28] лимитирующими условиями этого процесса будут следующие обстоятельства: во-первых, это «мероприятия государственной экономической политики, включая соответствующие законодательные нормы по банкротству, приватизации, антимонопольному регулированию и др.»; во-вторых, «внешние условия функционирования промышленных предприятий: рыночные структуры, состав и количество конкурентов, потребителей производимой продукции, барьеры входа на рынок, связи с правительственными учреждениями и банковской системой, принадлежность к сектору экономики, его специфические особенности, межотраслевые взаимодействия и т. д.»; в-третьих, «внутренняя организация работы промышленных предприятий, учитывающая накопленный опыт, уровень технологии и знаний, эффективность управления» [16, с. 28]. Соглашаясь с таким подходом, считаем, что для создания таких оптимальных условий (для перехода от модели выживания отечественных предприятий реального сектора экономики к модели новой индустриализации) в Республике Беларусь необходимо системно реализовать следующие мероприятия:

во-первых, продолжать формирование рыночной институциональной среды, способствующей развитию предпринимательской инициативы, включая соответствующие законодательные нормы: по банкротству, приватизации, антимонопольному регулированию и др.;

во-вторых, развивать институты общественно-государственно-частного партнерства, в том числе при планировании развития реального сектора экономики;

в-третьих, разработать систему мер по обеспечению промышленных предприятий дешевыми длинными деньгами в количестве, необходимом для быстрого проведения модернизации реального сектора экономики;

в-четвертых, при совершенствовании концепции развития промышленности в Республике Беларусь уделить внимание таким факторам как: 1) сбалансированность ресурсов, т.е. при строительстве новых и модернизации старых предприятий необходимо определить источники получения всех необходимых для этого ресурсов: человеческих, технологических, материальных, финансовых, предпринимательских, институциональных; 2) мероприятия по решению проблемы высвобождающейся (недостаточно квалифицированной) рабочей силы. Мировой опыт и здравый смысл говорят о том, что всех переучить не удастся и достаточно большое количество людей останется без работы. Последнее, если не принять надлежащих мер, может угрожать безопасности государства. Большие массы безработных людей, а в нашем случае и склонных к потреблению спиртного, всегда опасно; 3) разработка новых и совершенствование старых механизмов по «агрессивному» продвижению белорусских товаров и услуг за пределы страны. Принципиально новых идей в этой сфере пока нет. Вместе с тем без современной логистики, 
маркетинга, новейших форм и механизмов конкурентной борьбы реализации произведенной продукции и услуг будет постоянно сталкиваться с целым ворохом проблем;

в-пятых, разработать концептуальные предложения по механизмам повышения мотивации руководителей и трудовых коллективов государственных предприятий;

в-шестых, при планировании структурной динамики и технологической модернизации народного хозяйства учитывать демографические реалии Республики Беларусь, а именно то, что количество населения в трудоспособном возрасте будет постоянно сокращаться. Это необходимо учитывать при планировании новых рабочих мест. Также необходимо принимать во внимание слабую внутреннюю мобильность рабочей силы в нашей стране;

в-седьмых, окончательное решение о строительстве новых и модернизации существующих предприятий должно приниматься только после проведения комплексной социально-эколого-экономической экспертизы с учетом динамики истинных инвестиции;

в-восьмых, усилить роль социально-научного сообщества в совершенствовании принципов, механизмов и инструментов планирования социально-экономического развития страны, формировании структурной политики и технологической модернизации народного хозяйства.

\section{ВЫВОДЫ}

Выявлена взаимосвязь структурной политики государства и модернизации реального сектора экономики, что позволило сделать вывод о необходимости парадигмальной замены модели выживания отечественных предприятий реального сектора экономики на модель новой индустриализации, т. е. на формирование новой структуры народного хозяйства, основой которой должен стать сверхиндустриальный промышленный уклад. Установлено, что для создания оптимальных условий к модели новой индустриализации в Республике Беларусь необходимо системно реализовать следующие мероприятия: продолжать формирование рыночной институциональной среды, способствующей развитию предпринимательской инициативы; развивать институты общественно-государственно-частного партнерства, в том числе при планировании развития реального сектора экономики; разработать систему мер по обеспечению промышленных предприятий дешевыми длинными деньгами; совершенствовать концепцию развития промышленности в Республике; разработать концептуальные предложение по механизмам повышения мотивации руководителей и трудовых коллективов государственных предприятий; при планировании структурной динамики и технологической модернизации народного хозяйства учитывать демографические реалии Республики Беларусь; окончательное решение о строительстве новых и модернизации существующих предприятий должно приниматься только после проведения комплексной социально-эколого-экономической экспертизы с учетом динамики истинных инвестиции; усилить роль социально-научного сообщества в совершенствовании принципов, механизмов и инструментов планирования социально-экономического развития страны, формировании структурной политики и технологической модернизации народного хозяйства.

\section{СПИСОК ИСПОЛЬЗОВАННОЙ ЛИТЕРАТУРЫ}

1. Сухарев, О. С., Стрижакова, Е. Н. Индустриальная политика и развитие промышленных систем: Эволюция, институты и управление. - М.: ЛЕНАНД, 2015. - С. 9.

2. Ансофф, И. Новая корпоративная стратегия. - Спб.: Питер, 1997. - С. 53 
3. Асеев, А. Л. Без науки у России нет будущего / А. Л. Асеев // ЭКО. - 2010. № 1. - С. 15-33.

4. Мясникович, М. В. В новом веке движение вперед возможно только на научной основе [Электронный peсурс]. - Режим доступа: http://www.soyuzgos.ru/2008/ 22/22_07_Mjasnikovich.html. - Дата доступа: 22.02.2018.

5. Нанотехнологии как ключевой фактор нового технологического уклада в экономике» / С. Ю. Глазьев [и др] ; под ред. С. Ю. Глазьева, В. В. Харитонова. - М.: Тровант, 2009. $-304 \mathrm{c}$.

6. Наумович, О. А. Смена технологических укладов как социально-экономический феномен / О. А. Наумович // Экономическая наука сегодня: сборник научных статей; ред. кол.: Солодовников С. Ю. (пред. ред. кол.) [и др.]. - Минск: БНТУ, 2016. -№ 4. - С. 34-38.

7. Губанов, С. Об экономической модели и долгосрочной стратегии новой индустриализации России / С. Губанов // Экономист. - 2016. - № 2. - С. 3-10.

8. Фролов, Д. Кризис наноиндустрии и ее будущее / Д. Фролов, И. Полынцев // Экономист. - 2017. - № 5. - С. 27-37.

9. Солодовников, С. Ю. Современная структурная политика и кризис наноиндустрии / С. Ю. Солодовников // Право. Экономика. Психология. - 2017. - № 3 (8). - С. 49-55.

10. Мелешко Ю. В. Системообразующие принципы развития услуг промышленного характера/ Ю. В. Мелешко // Устойчивое развитие экономики: состояние, проблемы, перспективы сборник трудов ХІ международной научно-практической конференции. - 2017. - С. 84-86.

11. Мелешко, Ю. В. Значение услуг промышленного характера в повышении конкурентоспособности промышленных предприятий (в контексте четвертой промышленной революции) / Ю. В. Мелешко // Экономическая наука сегодня: сборник научных статей; ред. кол.: Солодовников С. Ю. (пред. ред. кол.) [и др.]. - Минск: БНТУ, 2017. - № 6. - С. 64-78.

12. Мелешко, Ю. В. Эволюция услуг промышленного характера в Республике Беларусь в 1995-2015 гг./ Ю. В. Мелешко // Экономическая наука сегодня: сборник научных статей; ред. кол.: Солодовников С. Ю. (пред. ред. кол.) [и др.]. - Минск: БНТУ, 2017. № 5. - С. 127-144.

13. Гурский, В. Л. Исследование теоретических основ нового качества экономического роста в контексте перехода к инновационному развитию Республики Беларусь и Российской Федерации / В. Л. Гурский, В. А. Клименко, В. В. Фаузер, Т. В. Сергиевич // Корпоративное управление и инновационное развитие экономики Севера: Вестник Научно-исследовательского центра корпоративного права, управления и венчурного инвестирования Сыктывкарского государственного университета. - 2017. - № 2. - С. 53-59.

14. Афанасьева, М. В. Особенности государственной промышленной политики в условиях модернизации технологической среды : автореф. дис. ... канд. экон. наук : 08.00.05 / М. В. Афанасьева. - Москва, 2011.

15. Лебедин, Н. Ю. Формирование экономики знаний как ключевое направление общественно-экономического развития / Н. Ю. Лебедин // Известия Санкт-Петербургского экономического университета. - 2017. - № 5. - С. 16-20.

16. Сухарев, О. С. Структурный анализ развития промышленной системы / О. С. Сухарев, Е. Н. Стрижакова // Национальные интересы: приоритеты и безопасность. - 2014. № 41(268). - C. 26-40.

\section{REFERENCES}

1. Suharev, O. S., Strizhakova, E. N. Industrial'naya politika i razvitie promyshlennyh sistem: Ehvolyuciya, instituty i upravlenie. - M.: LENAND, 2015. - S. 9. 
2. Ansoff, I. Novaya korporativnaya strategiya. - Spb.: Piter, 1997. - S. 53

3. Aseev, A. L. Bez nauki u Rossii net budushchego / A. L. Aseev // EHKO. - 2010. № 1. - S. 15-33.

4. Myasnikovich, M. V. V novom veke dvizhenie vpered vozmozhno tol'ko na nauchnoj osnove [EHlektronnyj resurs]. - Rezhim dostupa: http://www.soyuzgos.ru/2008/ 22/22_07_Mjasnikovich.html. - Data dostupa: 22.02.2018.

5. Nanotekhnologii kak klyuchevoj faktor novogo tekhnologicheskogo uklada v ehkonomike» / S. Yu. Glaz'ev [i dr] ; pod red. S. Yu. Glaz'eva, V. V. Haritonova. - M.: Tro-vant, 2009. $-304 \mathrm{~s}$.

6. Naumovich, O. A. Smena tekhnologicheskih ukladov kak social'no-ehkonomicheskij fenomen / O. A. Naumovich // EHkonomicheskaya nauka segodnya: sbornik nauchnyh statej; red. kol.: Solodovnikov S. Yu. (pred. red. kol.) [i dr.]. - Minsk: BNTU, 2016. -№ 4. - S. 34-38.

7. Gubanov, S. Ob ehkonomicheskoj modeli i dolgosrochnoj strategii novoj indu-strializacii Rossii / S. Gubanov // EHkonomist. - 2016. - № 2. - S. 3-0.

8. Frolov, D. Krizis nanoindustrii i ee budushchee / D. Frolov, I. Polyncev // Ehkonomist. - 2017. - № 5. - S. 27-37.

9. Solodovnikov, S. Yu. Sovremennaya strukturnaya politika i krizis nanoindu-strii / S. Yu. Solodovnikov // Pravo. EHkonomika. Psihologiya. - 2017. - № 3 (8). - S. 49-55.

10. Meleshko Yu. V. Sistemoobrazuyushchie principy razvitiya uslug promyshlen-nogo haraktera / Yu. V. Meleshko // Ustojchivoe razvitie ehkonomiki: sostoyanie, problemy, perspektivy sbornik trudov XI mezhdunarodnoj nauchno-prakticheskoj konferencii. - 2017. - S. 84-86.

11. Meleshko, Yu. V. Znachenie uslug promyshlennogo haraktera v povyshenii konkurentosposobnosti promyshlennyh predpriyatij (v kontekste chetvertoj promyshlennoj revolyucii) / Yu. V. Meleshko // EHkonomicheskaya nauka segodnya: sbornik nauchnyh statej; red. kol.: Solodovnikov S. Yu. (pred. red. kol.) [i dr.]. - Minsk: BNTU, 2017. - № 6. - S. 64-78.

12. Meleshko, Yu. V. EHvolyuciya uslug promyshlennogo haraktera v Respublike Belarus' v 1995-2015 gg. / Yu. V. Meleshko // EHkonomicheskaya nauka segodnya: sbornik nauchnyh statej; red. kol.: Solodovnikov S. Yu. (pred. red. kol.) [i dr.]. - Minsk: BNTU, 2017. - № 5. S. $127-144$.

13. Gurskij, V. L. Issledovanie teoreticheskih osnov novogo kachestva ehkonomicheskogo rosta $\mathrm{v}$ kontekste perekhoda $\mathrm{k}$ innovacionnomu razvitiyu Respubliki Belarus' i Rossijskoj Federacii / V. L. Gurskij, V. A. Klimenko, V. V. Fauzer, T. V. Sergievich // Korporativnoe upravlenie i innovacionnoe razvitie ehkonomiki Severa: Vestnik Nauchno-issledovatel'skogo centra korporativnogo prava, upravleniya i venchurnogo investirovaniya Syktyvkarskogo gosudarstvennogo universiteta. - 2017. - № 2. - S. 53-59.

14. Afanas'eva, M. V. Osobennosti gosudarstvennoj promyshlennoj politiki v usloviyah modernizacii tekhnologicheskoj sredy : avtoref. dis. ... kand. ehkon. nauk : 08.00.05 / M. V. Afanas'eva. - Moskva, 2011.

15. Lebedin, N. Yu. Formirovanie ehkonomiki znanij kak klyuchevoe napravlenie obshchestvenno-ehkonomicheskogo razvitiya / N. Yu. Lebedin // Izvestiya Sankt-Peterburgskogo ehkonomicheskogo universiteta. - 2017. - № 5. - S. 16-20.

16. Suharev, O. S. Strukturnyj analiz razvitiya promyshlennoj sistemy / O. S. Suharev, E. N. Strizhakova // Nacional'nye interesy: prioritety i bezopas-nost'. - 2014. - № 41 (268). S. $26-40$.

Статья поступила в редакциию 17 марта 2018 года. 